\title{
A Critical Assessment of Varner's Proposal for Consensus and Convergence in the Biomedical Research Debate
}

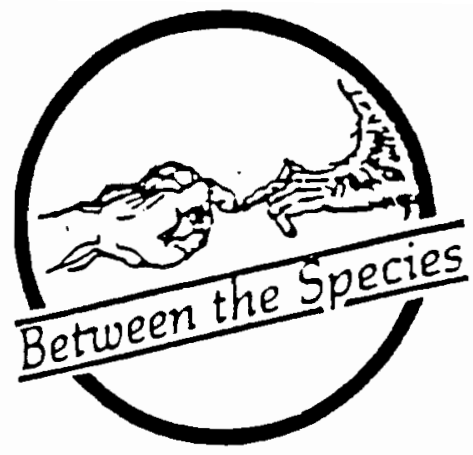

\author{
Alan C. Clune \\ State University of New York at Buffalo
}

Editors' Note: The original of this paper was presented at the Eastern Division meetings of the Society for the Study of Ethics and Animals, held in New York City, December, 1995.

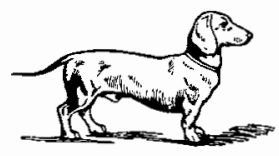

I

In "The Prospects for Consensus and Convergence in the Animal Rights Debate" Gary E. Varner attempts to provide a direction for reconciliation between utilitarian and inherent value views on the subject of biomedical research testing on nonhuman animals. ${ }^{1}$ These two views are opposed because the former allows some testing and the latter does not. In this paper I will argue that Varner's prospect fails because its implications are in too strong of an opposition to the inherent value view.

First, I will sketch those basics of Singer's and Regan's views that are relevant to our discussion. Second, I will critically analyze the attempt by Gary Varner to open the way for convergence between the utilitarian and the inherent value views. I will then critically analyze a principle used by Regan, the "worseoff" principle. Finally, out of these analyses I will suggest a new direction for exploration of the possibility of rapprochement between the utilitarian and inherent value views.
II

As expressed by Peter Singer, the utilitarian view holds that all interests of sentient individuals ${ }^{2}$ should be held to have equal value and that ethical decisions should be made in a manner that maximizes the aggregate positive outcomes in terms of those interests. ${ }^{3}$ This view allows some testing on nonhuman animals as long as the projected outcome for sentient creatures in general is a maximum.

The inherent value view, as expressed by Tom Regan, holds that individuals who have autonomy with regard to preferences are subjects-of-a-life and, therefore, have an inherent value. ${ }^{4}$ For Regan, this includes some nonhuman animals. ${ }^{5}$ Furthermore, any such individual has the right not to be harmed if that harm is for the benefit merely of other sentient individuals. According to Regan, this view allows no testing of nonhuman animals for purposes of biomedical research.

Although Regan holds that generally a subject-ofa-life cannot be harmed if the purpose is to benefit only other individuals, there are cases where he allows this guideline to be overridden. He allows it to be overridden, for example, in cases where it seems impossible not to harm an individual who has moral rights. Regan has two principles that can be employed in such cases: the mini-ride and worse-off principles.

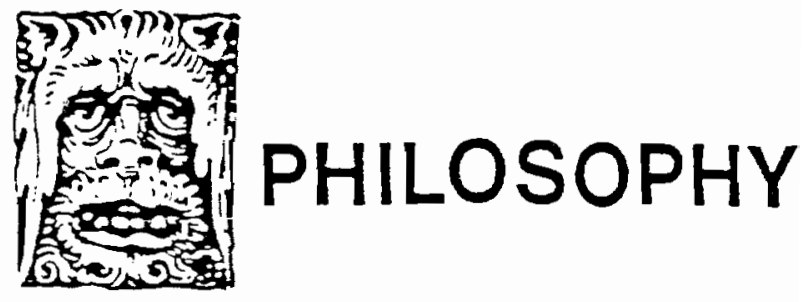


The mini-ride principle says that under circumstances of comparable harms, action should be taken so that the fewest possible are harmed. The idea here is that it is better, when you must violate the rights of individuals, that you engage in as few instances of it as possible. ${ }^{6}$ For our purposes, though, we are mainly interested in Regan's worse-off principle.

The worse-off principle says that under circumstances of noncomparable harms, individuals who stand to lose the most, in terms of the degree of their capacity to form and satisfy desires, ought not to be harmed. Consider Regan's application of this principle to the following exceptional case. ${ }^{7}$ There are five individuals in a lifeboat that can only support four. Four of the individuals are normal humans, and one of the individuals is a normal dog. Who ought to go overboard? The answer that the worse-off principle gives is that the dog ought to go overboard. The dog has a much less sophisticated capacity to form and satisfy desires, so he or she would be much less worseoff dead than any of the humans would be. Moreover, this principle implies that any number of dogs could be thrown overboard in order to save just one human.

Regan also holds that " $[w]$ hat the rights view implies should be done in exceptional cases...,including lifeboat cases,...cannot fairly be generalized to unexceptional cases." 8 And he also tells us that the worse-off principle "...applies in cases where we must choose between harming one innocent or harming another." Regan does not think that judgments made about "isolated, exceptional cases" can be transferred to practices on a normal institutional level. On an institutional level, one ought never to be put under the influence of circumstances that force one to choose between harming one of two innocent individuals.

\section{III}

In his article, Varner analyzes Singer's and Regan's views and proposes to show that although Regan's view seems to prohibit any nonhuman animal testing, on closer inspection, there does appear to be a possibility for continued discussion between the two sides.

Varner claims, on the basis of how the worse-off principle handles the lifeboat case, that "this principle, coupled with [Regan's] conception of harm, would seem to imply that at least some research is not only permissible but required, even on a true animal rights view." 10 Varner argues that since the death of a human being is noncomparably worse than the death of a nonhuman animal, "if we knew by performing fatal research on a given number of animals we could save even one human life, then the worse-off principle would apply, and it would require us to perform the research."11

Now, I think that Varner's claim here does not fully appreciate the necessity of constraining in some way the application of the worse-off principle. He imputes to Regan the view that what constrains the application of the worse-off principle is the need to acquire consent from subjects in order to place them at risk. ${ }^{12}$ But this is clearly wrong. What primarily constrains the worseoff principle is that it can only be applied in true lifeboat cases. And as we will see, by the time that any situation warrants the application of the worse-off principle, the issue of consent is moot.

Consider that in order for there to be a true lifeboat case, a group of individuals must naturally share equally in a set of threatening circumstances, as opposed to being purposely placed in such circumstances. ${ }^{13}$ Moreover, in true lifeboat cases the threatening circumstances are generally such that in order for most of the individuals to survive, one or some must undertake the full risk ${ }^{14}$ (which can result in death) in place of the others. And none of the individuals has a choice to opt out of the circumstances. In a true lifeboat case such as this, Regan tells us that the worse-off principle allows the other members of the lifeboat to forcibly throw the nonhuman animal (the dog) overboard. Therefore, in the event of a true lifeboat case, it is clear that even Regan does not require consent in order to apply the worse-off principle.

However, if I understand Varner correctly, what he and I disagree on is whether membership in a true lifeboat group must occur naturally. In other words, we disagree over whether it would be permissible in some cases purposely to transfer lifeboat risks, without consent, to individuals who do not naturally find themselves in the lifeboat group. Regan disallows this because on a rights view "risks are not morally transferable to those who do not voluntarily choose to take them." 15 However, Varner thinks, contrary to Regan, that there are at least some cases where people generally find it acceptable to transfer risks in this way. Varner provides us with three examples of such cases: 1) when military draft guidelines are modified in times of war; 2) when price support guidelines (e.g., for the farming industry) are modified; and 3) when we go to war. And on the basis of these cases, Varner thinks that 
the worse-off principle is sometimes applicable to individuals who are not naturally in the lifeboat.

The first two examples involve redistributing risks without explicit consent. However, as Varner acknowledges, if these types of policy decisions are made by a democratically elected government, one can argue that there is implicit consent from the people. Therefore, these examples are somewhat weak for his purposes. This is why he proposes (3). When country A and country B go to war, each country forces the people of the other country to take on risks that they presumably do not voluntarily choose to take on. It is on the basis of this third type of case that Varner contends that there are cases where it is generally agreed that we can morally transfer risks to those who do not voluntarily choose to take them. It is on the basis of this third type of case that Varner thinks that the worse-off principle can be applied to individuals who do not naturally find themselves in the lifeboat group. It is on the basis of this third type of case that Varner holds that there may be an opening for convergence and consensus in the debate between utilitarian and inherent value theorists about the use of animals in biomedical research.

The first problem that I have with this third case is that even if Vamer is correct that it is a clear case of transferring risks without consent, it is not clear that there is any analogy between this type of case and the types of cases at issue, viz., biomedical research cases. That is to say, there is no analogy that would remotely suggest that we would be justified in transferring risks in biomedical research cases. If Varner wants to suggest that because we can find this one very odd case (when two countries go to war) where transferring risks is acceptable, we are justified in transferring risks in all biomedical research cases where there is a human life at stake, his argument needs a lot of work.

The main disanalogy between transferring risk when going to war and when performing biomedical research to save a human life is that the justifications used in each case are of entirely different types. Country A may justify going to war with country $B$ because country $B$ represents a threat. In biomedical cases there is no such threat from nonhuman animals that would offer the kind of justification needed to violate them merely for human ends.

Of course, sensing a threat does not entirely comprehend the justifications one country might give for going to war against another country. Country A may go to war simply to take from country B what it wants or needs (wars of conquest). And this would, at first glance, seem analogous to the biomedical testing cases. However, a war of conquest is prima facie not a clear example of morally transferring risk; any more than mugging someone on the street corner to get what one needs is a clear example of morally transferring risk. Here, the analogy is tenuous at best.

As a result of these problems with Varner's war analogy, I think that even in support of the possibility of a continued dialogue between the two sides, Varner's argument needs a lot of work. What the argument really needs is an example of a case of the transferring of risk without consent that bears some resemblance to the biomedical research case. What I suspect is that there are no such cases where risks are morally transferable without consent except, perhaps, in those where the individuals involved naturally find themselves in the lifeboat group. And as argued above, the worse-off principle would apply in these situations without the need for consent.

The second problem that I have with this third case (of going to war) is that I'm not convinced that this is a clear case of transferring risks without consent. Any nation qua nation is prima facie an entity that must accept the possibility of going to war with other nations. So, just in virtue of being an individual member of a nation, one accepts the possibility that other nations might attack his or her nation. Therefore, in the same way that one accepts the risks transferred to him or her by the government that they help to elect, one accepts the risks transferred to him or her by the foreign nation that they implicitly accept as a potential enemy. Therefore, it is arguable that there is a kind of consent in cases such as (3), too. Again then, I think that what Varner's argument needs is a better example, and I suspect that there are none that will do the work his argument requires.

\section{IV}

Now, I do think that Regan's worse-off principle does provide an opening for fatal animal testing. However, it does not provide as wide an opening as Varner suggests. My problem with Varner's rendering of the implications of Regan's worse-off principle is that it is too quick to generalize the use of the worse-off principle to unexceptional cases. Regan rightly warns against this because it leads to a kind of perfectionism where the burdens of society are routinely shifted to the weaker and less valuable members so that the more 
perfect individuals can better excel. This would clearly violate the rights view, as it would routinely treat individuals possessing inherent value merely as a means to others' ends. ${ }^{16}$

How then does the worse-off principle provide an opening for fatal animal testing? Well, suppose that there are nonhuman animals who naturally find themselves in a lifeboat type group with humans in virtue of sharing the same disease. Within the confines of such a limited group, Varner's convergence argument works, for, according to Regan's view, the worse-off principle would be applicable to that group, and the nonconsenting nonhuman animal would be the obvious candidate for the testing. So, Varner's conclusion about Regan is correct, even though it does not apply to as large a group of nonhuman animals as his argument suggests. Only nonhuman animals who have membership in the relevant afflicted group (i.e., those who actually have the threatening condition) could be used for fatal testing.

Now, even though Regan's worse-off principle allows fatal nonhuman animal testing to the extent just mentioned, I think that there is good reason to hold that the nonhuman animal would not in fact be the obvious candidate for testing on a true rights view. I argue below that this is because the worse-off principle itself is contradictory to the general spirit of a rights view.

\section{$\mathbf{V}$}

Imagine that the five individuals in the lifeboat are all normal human beings. How would Regan's view handle such a case? According to Regan, the worse-off principle would not be applicable because the interests are comparable. And there does not seem to be a basis for making the decision according to the mini-ride principle either, for, even though this principle tells us to throw one individual overboard, it provides no guidelines to tell us which one. Each individual's capacities to form and satisfy desires are prima facie the same. Seemingly, there are no morally relevant criteria available for choosing which individual must go overboard. Therefore, neither of these principles provides an answer. For four of the five to survive, at least one individual must act unethically by throwing someone overboard, or someone must make the sacrifice voluntarily.

First, I would like to state that I am not looking for a solution to this problem. I want to argue that the lifeboat case where there are four humans and one nonhuman animal arguably presents the same difficulty as the lifeboat case where all the individuals are human beings. Therefore, it would not be possible to apply the worse-off principle to allow the sacrifice of the nonhuman animal.

Recall that the worse-off principle involves weighing, in some manner, the capacities of the individuals in the group to form and satisfy desires. This must mean something like the following: what determines the value of an individual's capacities is the potential number and quality of the desires the individual can form and the power that the individual can direct in satisfaction of these desires. The greater this number, quality and power, the worse off an individual would be if he or she were the one to be forced to make the sacrifice.

Now, suppose the lifeboat contained the President of the United States, a Ph.D. in astrophysics, Plato, Dostoyevsky, and a milkman. The milkman never received a high school education, is an active alcoholic, and beats his wife and children. He does not do much else. Sometimes he does not even deliver the milk. The rest of the members of the lifeboat group have lives full of varied interests and activities. Who goes overboard? It is more than likely that using the worse-off principle, and noting that this is a clear case of noncomparable harms, the milkman will be taking a swim. Regan has to allow this or run the risk of harboring speciesist motives behind his worse-off principle.

There are two clear reasons why people might be willing to accept the worse-off conclusion that the milkman should go overboard. However, neither of these reasons, I will argue, is sufficient to reach such a conclusion.

First, people might have doubts about the milkman's innocence. If the milkman is not innocent, then according to the worse-off principle, the other people in the group do not have an obligation to treat him equally. However, according to Regan, even if the milkman is guilty of something, the punishment for this must fit the crime. ${ }^{17}$ The harm inflicted by any punishment cannot be greater than the harm generally inflicted by the milkman. Therefore, the worst the others in the lifeboat could do to the milkman, without violating his inherent value, would be for them to get drunk, beat him, and occasionally refuse to give him milk. They could not throw him overboard.

The second reason people might favor the conclusion of the worse-off principle, as Regan himself 
does, is because the milkman's capacities for forming and satisfying desires are not as rich as those of the others in the lifeboat. Now, the assumption behind the application of the worse-off principle is that there is an objective standard by which to measure the richness, and therefore value, of an individual's life. But it seems clear to me that there is no possibility of such a standard. Absent an objective standard, only the standards of various groups would be available, e.g., the standards of Platonists or milkmen. However, to use a standard arrived at by some special interest group would be to ignore the very inherent value of subjects-of-a-life that Regan emphasizes.

In order to avoid discounting the subject in this way, one must require that the value of a subject's life be measured according to the subject's own point of view. This is because it is the having of a point of view about one's world in the first place that makes an individual into a subject-of-a-life and is the basis for attributing rights to such an individual. So, adopting the first-person perspective as a method of determining the value that one life has compared to another is consistent with valuing the subject over utility. Now, I think that no normal, healthy individual would judge himself or herself to be less valuable than another. If this is true, then no normal healthy individual could be thrown overboard for having a less valuable life. In such severe lifeboat cases then, it is not at all obvious that the subject-of-a-life who happens to be a dog is the one who should go overboard, no more than it is obvious that the milkman should go overboard.

Therefore, I think that we must conclude that Regan's worse-off principle has unacceptable consequences for a rights position. If I am correct, then the narrow opening for convergence that we were ready to grant Varner is also contrary to a rights view. All things considered then, the application of the worseoff principle is an unlikely place to find convergence and consensus in the biomedical research debate.

However, this failure does have potential for pointing us in another direction. All that we have to consider is a certain disanalogy between the milkman (or dog) lifeboat case and biomedical lifeboat cases generally. In the milkman lifeboat case, there were only two options available for resolution. Either some individual is forcibly thrown overboard in accord with the guidance of the worse-off principle (assuming that no one is willing to make a sacrifice), or all individuals would drown. I have not given a solution to this case but have only argued that the milkman case and the dog case present the same problem, to which the worseoff principle gives no solution compatible with a rights view. This implies that if there is no other solution forthcoming, then we would have to declare that in such cases, all must drown (assuming that this is not itself an unethical conclusion).

Fortunately, we are not seeking a solution to these types of cases. We are interested in biomedical lifeboat cases, and in biomedical lifeboat cases there is a third option available to the individuals in the lifeboat which is unavailable to the individuals in the milkman lifeboat. The individuals in the biomedical lifeboat can undergo biomedical testing in an attempt to save themselves. ${ }^{18}$ This direction distributes risks to those who stand to benefit from taking them, and leaves the decision up to each individual in the lifeboat as to whether the risks are reasonable. Of course, animals cannot make these decisions themselves. However, I think it is possible for panels of animal advocates to make these decisions for animals. These panels can be arranged so that the decisions made by them for animals approximate, to a good degree of accuracy, the decisions that average normal humans would make under similar circumstances. ${ }^{19}$

In order to find a solution to the rapprochement issue that does not violate the rights of individuals, but provides for the possibility of fruitful biomedical testing, I believe that exploiting the implications of this disanalogy between severe lifeboat cases (e.g., the milkman or dog case) and biomedical lifeboat cases is the direction to take. ${ }^{20}$

I would like to thank Gary Varner for his comments on the earlier draft of this paper.

\section{Notes} 24-28.

${ }^{1}$ In the Hastings Center Report, vol. 24, no. 1 (1994): pp.

${ }^{2}$ For Singer, this includes nonhuman animals.

${ }^{3}$ Peter Singer.Aninal Liberation (Avon, New York, 1975).

${ }^{4}$ Tom Regan. The Case for Animal Rights (University of California Press, Berkeley and Los Angeles, 1983).

${ }^{5}$ Regan draws the line for individuals that meet these criteria at normal mammals one year old or more. He does 
allow that this line is not set in stone, but given the current status of what we know, it's a reasonable place to start. Drawing such a line also allows one to get on with the pragmatic issue at hand without having to address any slippery slope objections. It is important to keep in sight the pragmatic goal of moving in the direction of respecting the rights of individuals who meet the criteria. The ultimate goal, of course, would be to recognize those rights in all who possess them. But including them all perhaps involves an historical process that moves in that direction incrementally in accord with the evidence for individuals' meeting the appropriate criteria.

${ }^{6}$ This is a principle motivated by violating as few cases of autonomy as possible, not by maximizing the overall good. However, the choice of action may sometimes be the same regardless of which of these principles one is guided by.

${ }^{7}$ Regan, 1983, p. 351.

${ }^{8}$ Ibid., p. 325.

${ }^{9}$ Ibid., p. 308.

10 Varner, 1994, p. 27.

${ }^{11}$ Ibid.

12 lbid.
${ }^{13}$ This occurs, for example, when an animal is purposely given a certain disease in order that he or she be useful for testing purposes.

${ }^{14}$ In lifeboat cases, where the threat is some medical condition or other, the risk to be undertaken is the risk associated with being the individual to undergo testing.

${ }^{15}$ Regan, 1983, p. 377.

${ }^{16}$ Regan wants to avoid any justification for the routine subordination of the rights of the individual which can occur in an institutional setting. In The Case for Animal Rights, see pp. 325,352 and 384-385.

${ }^{17}$ Ibid., pp. 290-91.

18 Of course, in some cases the situation is not life threatening. But the individuals could still undergo testing for whatever condition afflicts them.

${ }^{19}$ For more details on how this can be accomplished, see Clune, "Biomedical Testing on Nonhuman Animals: An Attempt at a Rapprochement between Utilitarianism and Theories of Inherent Value," The Monist, vol. 79, no. 2 (1996): pp. 230-246.

${ }^{20}$ Although it is beyond the scope of this paper to go into detail about this direction for rapprochement, I have done so elsewhere; see Clune, 1996.

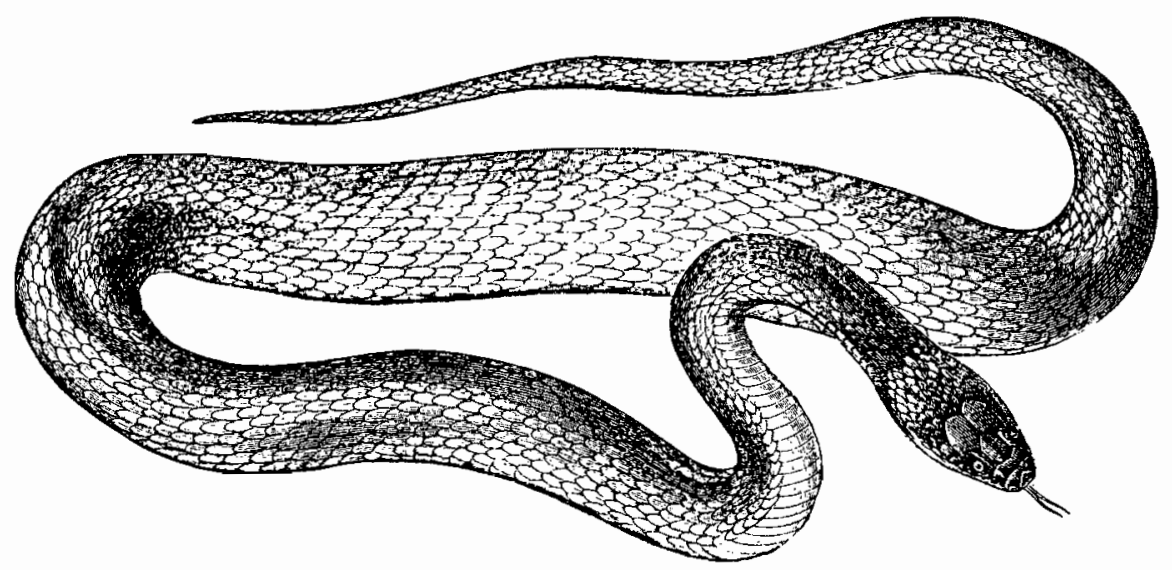

